\title{
LA INCOMPATIBILIDAD DE LAS ACCIONES FRENTE A LA PRESTACIÓN IRRISORIA SEGÚN EL CÓDIGO DE COMERCIO ECUATORIANO
}

\section{THE INCOMPATIBILITY OF THE REMEDIES AGAINST THE "PRESTACIÓN IRRISORIA" ACCORDING TO THE ECUADORIAN COMMERCIAL CODE}

Ornella Saavedra Velásquez*

\section{Resumen}

El nuevo Código de Comercio ecuatoriano introduce la figura de la prestación irrisoria en el art. 217. Su objetivo es asegurar que las prestaciones asumidas por cada uno de los contratantes sean simétricas. A pesar de ello, ofrece tres consecuencias incompatibles entre sí frente a una prestación irrisoria: la nulidad absoluta, la resolución del contrato y la adaptabilidad. Por tal motivo, se propone que la sanción apropiada debería ser la nulidad relativa, que es compatible con la adaptabilidad del contrato.

Palabras claves: prestación irrisoria; lesión enorme; nulidad absoluta; nulidad relativa; resolución de contrato.

\section{AbSTRACT}

The new Commercial Code enshrines the prestación irrisoria for the first time in our legal system. Its purpose is to ensure that the obligations that each contractual party acquires are symmetrical. Nonetheless, the Code offers three incompatible consequences should the contract have a prestación irrisoria: absolute nullity, resolution and adapting the contract. For that reason, we propose that the adequate consequence for a prestación irrisoria should be

* Egresada de la Facultad de Jurisprudencia de la Universidad de San Francisco de Quito en mayo 2020. Dirección Postal: Avenida Interoceánica y Pasaje Jijón y Caamaño, Cumbaya, Quito-Ecuador. Correo electrónico: Ornellasv97@hotmail.com. N. ${ }^{\circ}$ Orcid: https://orcid.org/0000-0002-1224-5887. Este trabajo de investigación fue presentado como el Trabajo de Titulación, requisito para la obtención del título de abogada. Se agradece a Oswaldo Santos Dávalos, quien fue una valiosa guía durante la realización de este estudio. Recepción: 2020-09-01; aceptación: 2020-11-16. 
the relative nullity, since that solution is compatible with the adaptation of the contract.

Keywords: contractual balance; gross disparity; laesio enormis; absolute nullity; relative nullity; termination of contract.

\section{INTRODUCCIÓN}

En el derecho contractual existe la noción llamada "equilibrio contractual", que posibilita a las partes, en virtud del principio de libertad negocial, a configurar el mejor escenario para alcanzar una simetría y equivalencia entre sus prestaciones. No obstante, este concepto es solo aplicable a los contratos onerosos y conmutativos, puesto que es requisito que las partes se graven cada una en beneficio de la otra y que consideren que sus prestaciones sean "equivalentes" entre sí. De acuerdo con Leandro Martins Zanitelli:

"la reciprocidad [de un contrato] [...] se traduce no solo en una mutualidad de costos y beneficios, sino también en la proporcionalidad (igualdad o similitud de proporción) entre el costo y el beneficio que obtiene cada uno de los contratistas"1.

Como sostienen los autores Patricia López ${ }^{2}$ y José Félix Chamie ${ }^{3}$, este principio presupone, junto con el de la buena fe contractual, que la desproporción acaecida en la celebración del contrato (equilibrio original) o durante la ejecución (equilibrio funcional), debe enmendarse para evitar cualquier abuso instrumental de la figura contractual, en que se puede llegar a beneficiar de manera injustificada una de las partes. El equilibrio original o congénito es aquel que se da al momento de la formación del contrato y se puede llegar a romper en casos como el aprovechamiento por una de las partes de los ciertos estados de debilidad de la otra, para la obtención de alguna ventaja patrimonial injustificada o cuando el valor de la cosa enajenada es en gran medida desproporcionado. Tal es el caso de la institución de la lesión enor$\mathrm{me}^{4}$. Por otro lado, el equilibrio funcional es aquel en que debe observarse que no exista ningún tipo de asimetría al momento de la ejecución de las obligaciones por causas externas a la voluntad de las partes, resultándole de ese modo más oneroso al deudor el cumplimiento de su obligación. Como sucede, por ejemplo, con la excesiva onerosidad sobreviniente.

Teniendo en cuenta que el principio general que rige a los contratos es el pacta sunt servanda, que se nutre de algunos fundamentos para que el contrato

\footnotetext{
${ }^{1}$ Zaniteldi (2011), p. 182.

${ }^{2}$ LÓPEZ (2015), pp. 133-144.

${ }^{3}$ Chamie (2008), pp. 116-117.

${ }^{4}$ Barceló (2018), p. 69.
} 
perdure en el tiempo como la buena fe, la equidad, la justicia contractual, entre otros, cabe afirmar que este brinda remedios que busca que los contratos se cumplan y se puedan ejecutar. Es por ello que en caso de existir un desequilibrio, ya sea en la formación o en la ejecución del contrato, el derecho se ha encargado de encontrar métodos para restablecer la base negocial inicial por la cual las partes quisieron entre sí vincularse, dándole la opción a la parte perjudicada entre solicitar la modificación o adaptabilidad de los términos del contrato para corregir la desproporción, puesto que ambas partes son conscientes de que tendrían un mayor perjuicio en dejarlo sin efecto, o pedir la anulación o terminación del contrato si considerase que no habría justificación económica para seguir atado a él o al ver que no se logra alcanzar una armonía ${ }^{5}$.

Existen algunas figuras jurídicas como la excesiva desproporción, lesión enorme o la excesiva onerosidad sobreviniente, que tratan de preservar el balance contractual. En varios países ya han sido reguladas de manera explícita en sus códigos civiles o comerciales, como es el caso de Alemania ${ }^{6}$, Suiza $^{7}$, México $^{8}$, Italia ${ }^{9}$, Brasil $^{10}$, Argentina ${ }^{11}$ y algunas normas del soft law ${ }^{12}$.

El problema surge cuando una legislación pretende ser innovadora y trata de incorporar una nueva figura al ordenamiento jurídico pensando que hace un cambio importante y moderno, y más que todo termina haciendo todo lo opuesto, al inspirarse en diferentes disposiciones legales de distintos lugares sin tomar en consideración las consecuencias jurídicas que se podrían generar en el sistema jurídico. Tal es el caso de la figura de la prestación irrisoria que se introdujo en el nuevo Código de Comercio ecuatoriano ${ }^{13}$, dado que, en aras proteger el equilibrio contractual, da como alternativas tres remedios incompatibles entre sí: la nulidad absoluta, la resolución del contrato y la adaptabilidad. Es por tal razón que este trabajo, a través de las normas que dispone el Código Civil para la interpretación de la ley, la doctrina internacional y normas del soft law como los Principios Unidroit, se encargará de esclarecer cual es la acción indicada frente a la figura de la prestación irrisoria mediante una correcta propuesta al art. 217 del Código de Comercio ecuatoriano.

Además, se buscará resolver el problema estableciendo que el remedio pertinente a la figura en cuestión es la nulidad relativa por ser conciliable con la adaptación del contrato. Para eso, se examinará, en la primera sección, las influencias de otras figuras afines con la prestación irrisoria; luego, en la segunda sección, se estudiará, de manera individual, las acciones que pro-

\footnotetext{
${ }^{5}$ Barceló (2018), pp. 189-215.

${ }^{6}$ Arts. 138.2 y 313 del $B G B$.

${ }^{7}$ Art. 21 del Código Civil suizo.

${ }^{8}$ Art. 17 del Código Civil de México.

${ }^{9}$ Arts. 1448, 1469-476 del Código Civil italiano.

${ }^{10}$ Arts. 157, 478, 479 y 480 del código civil brasileño

${ }^{11}$ Arts. 332 y 1091 del Código Civil y Comercial argentino.

${ }^{12} \mathrm{Tal}$ es el caso de los PCCI, PECL, DCFR.

${ }^{13}$ Art. 217 del Código de Comercio, ecuatoriano.
} 
pone esta nueva institución y, por último, en la tercera sección, se realizará un análisis del por qué la nulidad relativa y la adaptación del contrato son las acciones adecuadas frente a la prestación irrisoria.

\section{LA INFLUENCIA DE OTRAS FIGURAS AFINES CON LA PRESTACIÓN IRRISORIA}

Cuando se analiza el contenido de la disposición de la prestación irrisoria, se puede deducir que esta figura ha sido influenciada por diferentes instituciones jurídicas de distintos sistemas legales, como:

1. la excesiva desproporción de los Principios Unidroit sobre los Contratos Comerciales;

2. la lesión enorme del derecho continental y

3. el Inequality of Bargaining Power \& Unconscionability Doctrine del derecho anglosajón.

\section{La excesiva desproporción de los Principios Unidroit sobre los Contratos Comerciales Internacionales}

La excesiva desproporción -Gross Disparity- apareció regulada como una figura jurídica en los Principios Unidroit en el año 1994, en el art. 3.10 (en la actualidad 3.2.7 en la versión 2016), que prescribe lo siguiente:

“(1) Una parte puede anular el contrato o cualquiera de sus cláusulas si en el momento de su celebración el contrato o alguna de sus cláusulas otorgan a la otra parte una ventaja excesiva. A tal efecto, se deben tener en cuenta, entre otros, los siguientes factores:

(a) que la otra parte se haya aprovechado injustificadamente de la dependencia, aflicción económica o necesidades apremiantes de la otra parte, o de su falta de previsión, ignorancia, inexperiencia o falta de habilidad en la negociación; y

(b) la naturaleza y finalidad del contrato.

(2) A petición de la parte legitimada para anular el contrato, el tribunal podrá adaptar el contrato o la cláusula en cuestión, a fin de ajustarlos a criterios comerciales razonables de lealtad negocial.

(3) El tribunal también podrá adaptar el contrato o la cláusula en cuestión, a petición de la parte que recibió la notificación de la anulación, siempre y cuando dicha parte haga saber su decisión a la otra inmediatamente, $y$, en todo caso, antes de que ésta obre razonablemente de conformidad con su voluntad de anular el contrato. Se aplicará, por consiguiente, el párrafo (2) del Artículo 3.10"14.

\footnotetext{
${ }^{14}$ PCCI.
} 
Resulta importante analizar los elementos y consecuencias de esta figura, puesto que si se compara con la redacción de art. 217 del Código de Comercio ecuatoriano ${ }^{15}$, se puede llegar a la conclusión de que el legislador tomó ciertas partes de esta disposición y la adaptó a la legislación ecuatoriana, realizando algunos cambios de cierta trascendencia. Tanto así, que ha establecido tres remedios para la prestación irrisoria, dos de ellos no contemplados en los Principios Unidroit: la nulidad absoluta y la resolución del contrato.

La excesiva desproporción está consolidada por tres elementos: uno objetivo o sustancial y por otros dos subjetivos o procedimentales. El objetivo es aquel que está relacionado con el resultado del contrato o con el desequilibrio económico, el cual debe configurarse al momento de celebrarse el contrato ${ }^{16}$. Esteve Bosch Capdevila lo define

"en el sentido que la situación de debilidad puede provocar que se pague un precio muy superior o se reciba una contraprestación de valor muy inferior al que sería normal”"

De acuerdo con los Comentarios Oficiales de los Principios Unidroit, debe haber un "desequilibrio en el que las circunstancias sean impactantes para conmocionar la conciencia de una persona razonable" 18 . Este elemento se refleja en la ventaja excesiva. A diferencia de la lesión enorme, no se recurre a fórmulas aritméticas para determinar si existe o no una ventaja excesiva, por lo que quedaría a discreción del tribunal valorar aquellos escenarios ${ }^{19,20}$.

${ }^{15}$ Art. 217.- Se entiende por prestación irrisoria, aquella que es ínfima, inequivalente o desequilibrada en relación a la contraprestación del otro contratante.

Para determinar si se trata de una prestación irrisoria, ya sea que constituya la totalidad del contrato o una o más de sus cláusulas, se deberá tener en consideración, entre otros, los siguientes factores:

a) Que la otra parte se haya aprovechado injustificadamente de la dependencia, aflicción económica o necesidades apremiantes de la otra parte, o de su falta de previsión, ignorancia, inexperiencia o falta de habilidad en la negociación; $y$,

b) La naturaleza y finalidad del contrato.

Cuando la prestación de una de las partes sea irrisoria en su monto, en consideración a la contraprestación de la otra parte, no habrá contrato conmutativo o de prestaciones correlativas, y en consecuencia el contrato o cláusula será absolutamente nulo.

A petición de la parte legitimada para resolver el contrato, el órgano jurisdiccional podrá adaptar el contrato o la cláusula en cuestión, a fin de ajustarlos a criterios comerciales razonables de lealtad negocial.

${ }^{16}$ Carranza (2006), pp. 10-12.

${ }^{17}$ VAQUer, Bosch y SáncheZ (2012), tomo I, pp. 491-497.

18 "What is required is that the disequilibrium is in the circumstances so great as to shock the conscience of a reasonable person", Comentario oficial del art. 3.2.7, de los PCCI.

${ }^{19}$ Se trató de hacer referencia al Comentario oficial del artículo de Hardship, en el que se mencionaba que se entenderá como onerosa la prestación cuando exista una alteración del $50 \%$ o más del costo o el valor de la prestación. No obstante, en 2004 el Comentario oficial fue revisado y hoy ya no existe dicha referencia.

${ }^{20}$ Bonell (1995), p. 88; Du Plessis (2009), pp. 449-457; Barceló (2018), pp. 200-201; Carranza (2006), p. 9; Papayannis (2005), p. 92. 
Por otro lado, los elementos subjetivos corresponden a la conducta de los contratantes, esto es: el aprovechamiento injustificado de una de las partes y la necesidad, inexperiencia, falta de previsión, ignorancia o falta de habilidad en la negociación de la contraparte ${ }^{21}$. Debido a la circunstancia que está atravesando una de las partes, la otra aprovecha la ocasión para obtener un beneficio patrimonial excesivo, que no se habría producido si se hubiera estado en igualdad de condiciones. Michael Bonnel señala que hay casos donde una de las partes, sin aprovecharse de la debilidad de la otra, puede obtener una desproporción que dependería de la "naturaleza y finalidad del contrato"22.

Existe una discusión doctrinaria acerca si la persona que obtiene un beneficio debe o no de tener conocimiento acerca de la debilidad de la parte que busca la anulación o la modificación del contrato, y si además debe realizar otra acción. Jacques du Plessis menciona que el artículo referente no exige de manera literal que la persona acusada conozca o deba conocer

"de la dependencia, aflicción económica o necesidades apremiantes de la otra parte, o de su falta de previsión, ignorancia, inexperiencia o falta de habilidad en la negociación" ${ }^{23}$;

de hecho, argumenta que puede protegerse "de manera indirecta" arguyendo que, al no tener un conocimiento real de la debilidad, indica que no se 200 pudo aprovechar de forma injusta y, por lo tanto, el beneficio obtenido no se recibió de manera injustificada ${ }^{24}$.

En cambio, Rosa Barceló, Gemma Rubio, Alejandro Borda ${ }^{25}$ y Diego Papayannis creen que es necesario que el que se aprovecha de la situación del afectado tenga un simple conocimiento de ella. En este sentido, Rosa Barceló y Gemma Rubio expresan: "se intuye que la parte que obtiene una ventaja ha conocido las deficiencias subjetivas de la otra (o al menos tenía el deber de conocerlas)"26. Para otros, como Julio Cesar Rivera ${ }^{27}$ y Jorge Carranza el mero conocimiento no es suficiente; por el contrario, se requiere además de una conducta por parte del aprovechador para la obtención de un beneficio. En palabras de Jorge Carranza,

"en un primer momento la conducta del aprovechador se reduce al conocimiento de la situación del afectado, siendo necesario posteriormente

${ }^{21}$ Carranza (2006), p. 10; Barceló y Rubio (2014), pp. 159-160.

22 "In exceptional cases, even where no abuse of a superior bargaining position occurs, a party's advantage may be unjustifiably dependent upon the "nature and purpose of the contract”. BONELL (1995), p. 89.

${ }^{23}$ Art. 3.2.7. de los PCCI.

${ }^{24}$ Du Plessis (2009), pp. 449-457.

${ }^{25}$ Borda (2003), pp. 46-54.

${ }^{26}$ Barceló y Rubio (2014), pp. 159-160.

${ }^{27}$ Rivera (s/a), pp. 346-358. 
el despliegue de una conducta orientada a obtener de aquel una ventaja excesiva"28.

Las consecuencias que propone el art. 3.2.7 de los Principios Unidroit son dos. Por un lado, la anulación del contrato con la respectiva restitutio in integrum y, por el otro, la adaptación del mismo o de una de sus cláusulas. Como bien dice Jacques du Plessis, esta disposición permite que un contrato o una de sus disposiciones se anulen a petición de la víctima o que se modifiquen; en caso de querer esta última, el contrato deja de anularse ${ }^{29}$. La parte perjudicada, en virtud de los arts. 3.2.11 y 3.2.12 deberá notificar a la otra parte en un plazo razonable en caso de querer anular el contrato o una de sus cláusulas ${ }^{30}$. De acuerdo con el primer numeral del art. 3.2.12, el plazo razonable comienza desde el momento que la parte afectada tuvo conocimiento o no podía ignorar los hechos relevantes o haber sido capaz de actuar libremente ${ }^{31}$. El efecto de la anulación, de acuerdo con el art. 3.2.14, es la retroactividad de las obligaciones ${ }^{32}$, por lo que surge la restitutio in integrum, contemplada en el art. 3.2.15

No obstante, puede ocurrir que una de las partes contratantes haya tenido o pueda llegar a tener un provecho del contrato o de una parte de él, por lo que le resultaría arriesgado anularlo. Por tal razón, se prevé la posibilidad de que se solicite al órgano competente adaptar el contrato o una de sus cláusulas, para que esté conforme a "los estándares comerciales razonables de la lealtad negocial". Este artículo, a diferencia del 217 del Código de Comercio, faculta tanto a la parte perjudicada como a la que recibió la notificación de anulación en solicitar dicha adaptabilidad. La aplicación de este derecho excluye la aplicación al derecho a pedir la anulación, según el art. 3.2.10 ${ }^{34}$.

En cualquiera de los dos derechos alternativos, existe la facultad de exigir los daños y perjuicios ocasionados por la excesiva desproporción. Acorde con el art. 3.2.16, indistintamente que se haya anulado el contrato o una de sus cláusulas, se impone al responsable el deber de resarcir a la parte que conoció o debió conocer la causa de anulación. El artículo no detalla de manera explícita que se deba resarcir los daños en la adaptabilidad, pero se llega a intuir en la parte que se expresa "independientemente de que el contrato sea anulado o no" 35 .

\section{La lesión enorme del derecho continental}

La lesión enorme ha sido una de las figuras clásicas que, de igual manera, ha inspirado la redacción del artículo de la excesiva desproporción, de acuerdo

\footnotetext{
${ }^{28}$ Carranza (2006), p. 13.

${ }^{29}$ Du Plessis (2009), pp. 449-457.

${ }^{30}$ Art. 3.2.11. de los PCCI.

${ }^{31}$ Art. 3.2.12. de los PCCI.

${ }^{32}$ Art. 3.2.14. de los PCCI.

33 Ibid.

${ }^{34}$ Art. 3.2.10. de los PCCI.

${ }^{35}$ Art. 3.2.16. de los PCCI.
} 
con los antecedentes señalados por Jacques du Plessis, Ernst Kramer ${ }^{36}$ y otros autores $^{37}$. Esta institución se aplica cuando existe un quebrantamiento en el equilibrio contractual al momento de la perfección del contrato, ocasionado por la desproporción patrimonial entres las prestaciones. Tal como lo manifiesta Arturo Alessandri Rodríguez, "la lesión no es un vicio del consentimiento, ni el resultado del dolo de los contratantes, sino el perjuicio pecuniario que sufre uno de ellos" ${ }^{38}$.

En Ecuador, la normas que regulan esta figura han establecido un mínimo para ver si existe una desproporción en la prestación, por lo que se recurre a una fórmula matemática. El art. 1829 del Código Civil prescribe que:

"el vendedor sufre de lesión enorme cuando el precio que recibe es inferior a la mitad del justo precio de la cosa que vende; y el comprador, a su vez, sufre lesión enorme cuando el justo precio de la cosa que compra es inferior a la mitad del precio que paga por ella" 39 .

$\mathrm{El}$ art. 1830 dispone el efecto de la lesión, mismo que otorga al comprador a consentir en la recisión o completar el justo precio con la deducción de la décima parte o, en caso de ser el vendedor, consentir en la recisión o aumentar el exceso del justo precio aumentado en su décima parte ${ }^{40}$.

En efecto, la Corte Suprema de Justicia se ha pronunciado sobre los re202 quisitos que deben cumplirse para que pueda proceder la acción de rescisión por lesión enorme, estos son:

1) corresponde únicamente aquel de los contratantes que ha sido lesionado en los términos del art. 1829 y

2) debe plantearse dentro del término de cuatro años, contados desde la fecha del contrato ${ }^{41}$.

Cabe mencionar que, como figura excepcional, la lesión enorme se produce en los casos que la ley se remite a ella, tal es el caso de la compraventa y permuta de bienes inmuebles, cláusula penal enorme, partición de bienes y las asignaciones testamentarias.

De manera tradicional, la lesión enorme ha considerado solo el elemento objetivo, es decir, la observancia exclusiva del desequilibrio económico de las prestaciones. Legislaciones como la chilena, colombiana y ecuatoriana aún conservan dicha visión en sus Códigos Civiles. En cambio, la excesiva desproporción o la llamada prestación irrisoria en el Código de Comercio ecuatoriano, requiere que, además de que exista una desproporción en las prestaciones de las partes, se verifique un elemento subjetivo, que versa sobre

\footnotetext{
${ }^{36}$ Kramer (1999), p. 283.

${ }^{37}$ Yildirim (2008), p. 96; Chamie (2010), p. 7.

${ }^{38}$ Alessandri Rodríguez (2003), p. 754.

${ }^{39}$ Art. 1829 del Código Civil ecuatoriano.

${ }^{40}$ Art. 1830 del Código Civil ecuatoriano.

${ }^{41}$ Causa n. ${ }^{\text {o } 228-2004}$ (2006).
} 
las circunstancias en que se encuentran los contratantes al momento de la conclusión del contrato.

Asimismo, otra diferencia que se encuentra en la aplicación de ambas figuras es que la lesión enorme solo procede en la compraventa de bienes inmuebles. En cambio, en la prestación irrisoria, el art. 217 del Código de Comercio no detalla si esta institución aplica a los bienes muebles, inmuebles o a ambos. No obstante, el art. 373 del mismo cuerpo normativo dispone que para los contratos de venta comercial de bienes raíces se aplicará las reglas de la figura de la lesión enorme del Código Civil ${ }^{42}$. En consecuencia, se presume que la venta comercial de bienes inmuebles no solo se encuentra protegida por la lesión enorme, sino, también, por la prestación irrisoria, en virtud del art. 8 del Código Civil que prescribe que "a nadie puede impedirse la acción que no esté prohibida por la ley" ${ }^{43}$.

\section{Inequality of Bargaining Power y la Unconscionability Doctrine del derecho anglosajón}

Se ha entendido por la doctrina de la "desigualdad de poder en la negociación" cuando una de las partes del negocio tiene un mayor poder sobre la otra, pero esto no quiere decir que las Cortes solo deben concentrarse a analizar la posición de desigualdad; por el contrario, el deber es observar el abuso de una de las partes ejerciendo sobre la parte débil influencias indebidas o ciertas presiones ${ }^{44}$. Esta doctrina se consolidó especialmente en el derecho contractual después de la adopción del $U C C$, mismo que permitía a los jueces analizar el poder de la negociación de las partes intervinientes bajo la doctrina de las cláusulas abusivas (unconscionability doctrine $)^{45,46}$.

En efecto, las Cortes americanas no han definido un concepto claro de esta doctrina. De hecho, se ha dividido en dos vertientes:

1) la falta de alternativas significantes de la parte débil, la necesidad, naturaleza de bienes o servicios y la incapacidad de negociar los términos, $\mathrm{y}$

2) las Cortes suelen emplear factores relacionados con las características de las partes y de las transacciones.

Las características que los tribunales usan para apoyar la desigualdad del poder en la negociación incluyen: riqueza, sofisticación comercial, educación o conocimiento, genero, "tamaño" de las partes, poder de monopolio y estado de consumidor ${ }^{47}$. De acuerdo con Daniel Barnhizer no hay un estándar judicial para determinar la asimetría de poder de la negociación, por lo que resulta una doctrina oscura.

\footnotetext{
${ }^{42}$ Art. 373 del Código de Comercio ecuatoriano.

${ }^{43}$ Art. 8 del Código Civil ecuatoriano

${ }^{44}$ Alias \& Abdul (2012), pp. 331-334.

${ }^{45}$ Barnhizer (2005), pp. 194-195.

${ }^{46}$ Traducción libre.

${ }^{47}$ BARnhizer (2005), pp. 194-195.
} 
Por otro lado, la doctrina de lo inconcebible describe situaciones donde una parte toma cierta ventaja de la debilidad de la otra, consiguiendo así un trato injusto en la relación. Existe un examen para calificar si procede o no esta doctrina, y lo es si se prueban dos elementos: el procedimental y el sustancial ${ }^{48}$. El primer elemento trata de que una de las partes se encuentre en una circunstancia de vulnerabilidad (e.g. habilidad reducida, estado de necesidad, dependencia económica). El segundo elemento ocurre cuando la otra parte se aprovecha de la vulnerabilidad o de la discapacidad especial, lo cual es prueba suficiente para saber que el contrato es en sustancia injusto.

El $U C C$ prescribe:

"si el tribunal, por ley, considera, que el contrato o cualquier de sus cláusulas [...] fue inconcebible al momento de celebrarlo, puede negarse a hacer cumplir el contrato" ${ }^{49}$.

Asimismo, el comentario oficial a esta sección señala que la doctrina es para la "prevención de la opresión y la sorpresa injusta [...] y para la no perturbación de la asignación de riesgos debido al poder superior de la negociación"

Tanto la desigualdad de poder en la negociación como la doctrina de lo inconcebible inspiraron lo que es hoy el art. 3.2.7 de los Principios Unidroit. 204 Se dice que en el borrador del proyecto el art. 7 se titulaba unequal bargaining power, el cual combinaba los elementos procedimentales de aprovechar la debilidad con el elemento sustancial ${ }^{51}$. En cambio, el art. 8 titulado unconscionability, se centró en la sustancia, por lo que requirió la existencia de una disparidad desmesurada entre una de las obligaciones de las partes que perturben el equilibrio contractual ${ }^{52}$.

Como estas dos cláusulas estaban correlacionadas, se consideró combinarlas en un solo artículo, dando origen a la ventaja excesiva, elemento que está conectado con la sustancia del contrato. A su vez, esta ventaja excesiva se debe dar de manera injustificada, es decir, sin razón alguna, por lo que da como resultado al aprovechamiento injusto de la debilidad. Este último elemento se encuentra relacionado con la parte procedimental.

Finalmente, una vez expuestas estas tres figuras afines con la prestación irrisoria presente en nuestra legislación actual, es necesario remitirse a los remedios incompatibles que propone el art. 217 del nuevo Código de Comercio.

\footnotetext{
${ }^{48}$ Alias \& Abdul (2012), pp. 334-336.

${ }^{49} \S 2-302(1)$ of $U C C$.

${ }^{50}$ Ibid.

${ }^{51}$ Du Plessis (2009), pp. 449-457.

${ }^{52}$ Ibid.
} 
III. LOS REMEDIOS INCOMPATIBLES QUE PROPONE EL ART. 217

DEL CÓDIGO DE COMERCIO SOBRE LA PRESTACIÓN IRRISORIA

Como se mencionó con anterioridad, el art. 217 del Código de Comercio regula la nueva institución de la prestación irrisoria, proponiendo en su redacción tres remedios diferentes e incompatibles entre sí a la hora de proteger a la parte más débil. Estos son:

1. la nulidad absoluta,

2. la resolución del contrato y

3. la adaptabilidad.

Por todo esto, resulta necesario explicar la razón de ser de cada una de ellas y entender por qué no pueden coexistir como una solución al mismo problema.

\section{Nulidad absoluta}

La nulidad, de manera amplia, es definida por George Lutezco como una

"sanción inherente a todo acto jurídico celebrado sin observar las reglas establecidas por la ley, para asegurar la defensa del interés general, o para expresar la protección de un interés privado" ${ }^{53}$.

En esencia, es considerada como una sanción grave al negocio jurídico e implica que no produzca todos sus efectos propios, produciendo efectos retroactivos una vez declarada. Esta ha sido clasificada en función de los intereses que se busca proteger, sea en nulidad absoluta cuando protege el interés general o nulidad relativa cuando defiende el interés propio de las partes contratantes.

La nulidad absoluta se ha entendido como aquella en el que su defecto es sustancial y permanente ${ }^{54}$. El elemento sustancial determina que el defecto contraviene las normas que regulan al orden público. Esto se observa en el art. 1698 del Código Civil 55 . Por otro lado, el elemento de la permanencia significa que el vicio, además de configurarse al momento en que se otorgó el acto, subsiste; negando a que estos actos se puedan sanear o convalidar, ya sea a través de la ratificación o prescripción ${ }^{56}$. Esto se verifica en la última parte del art. $1699^{57}$. El Código Civil prohíbe, en la nulidad absoluta, la ratificación por una de las partes dado que el interés general se encuentra "fuera del alcance de la autonomía de la voluntad" 58 y, por tal razón, las partes intervinientes del negocio no pueden disponer de ello.

\footnotetext{
${ }^{53}$ Magallón (1997).

${ }^{54}$ Rivera (1994), pp. 889-890; LaCruZ y otros (1994).

${ }^{55}$ Art. 1698 del Código Civil ecuatoriano.

${ }^{56}$ Magallón (1997); Lacruz y otros (1994).

${ }^{57}$ Art. 1699 del Código Civil ecuatoriano.

${ }^{58}$ Coronel y Del Bruto (2011), p. 201.
} 
Aunque dicho artículo señala de manera literal que se entiende saneada la nulidad absoluta por el lapso de quince años, la doctrina ha interpretado de dos maneras esta parte de la disposición. Una parte ha entendido que después del transcurso de este tiempo se entiende válido el negocio, es decir, como si nunca hubiere existido el defecto que lo invalidaba ${ }^{59}$. Otra parte interpreta que se trata de la prescripción de la acción de nulidad, misma que no conllevaría la desaparición del vicio ${ }^{60}$. Esto último, significa que no podrían intentar la acción las personas que tengan un interés en ello, pero permitiría a que el juez la declare de oficio si tiene conocimiento en la causa, puesto que lo que prescribe es la acción de las partes de solicitar la nulidad, mas no la potestad del juez.

Por el fundamento que pretende tutelar la nulidad absoluta, se reconoce la legitimación activa a toda persona que tenga un interés en ello, aunque no haya sido parte del negocio jurídico, para solicitar la declaración judicial. La doctrina ha aclarado que esta legitimación no se la debe confundir con la noción de una acción popular ${ }^{61}$. Por tal razón, la Corte Suprema de Justicia ha determinado que el tercero que busca la declaración debe probar y "justificar un interés pecuniario y actual" ${ }^{62}$. Asimismo, se otorga la facultad de solicitar la nulidad a cualquiera de las partes del negocio jurídico, menos a quien conocía o debía conocer del vicio sobre la base del principio de que nadie se puede beneficiar de su propio dolo ${ }^{63}$.

206 El Código Civil, además, le da la potestad al juez en declarar la nulidad de oficio ${ }^{64}$. Para esto es necesario que se cumplan dos requisitos: que el juez tenga conocimiento de la causa y que el vicio aparezca de manifiesto ${ }^{65}$. Esto quiere decir que el juez no puede declarar la nulidad si no se ha introducido el contrato al proceso, ni tampoco cuando el vicio requiere de otros elementos probatorios para confirmar su existencia.

Por último, la nulidad absoluta es un régimen de excepción y, por lo tanto, solo opera en aquellas causales establecidas en la ley. El Código Civil, en el art. 1698, enumera de manera taxativa los supuestos en los que cabe declarar este tipo de nulidad: primero, cuando el objeto, causa o ambos del negocio jurídico es ilícito; segundo, cuando se omiten las solemnidades establecidas en la ley; y, tercero, cuando el negocio es realizado por un incapaz absoluto. $\mathrm{Al}$ final, menciona que cualquier otro tipo de vicio no contemplados en el artículo acarrea la nulidad relativa.

\footnotetext{
${ }^{59}$ Coronel y Del Bruto (2011), p. 201.

${ }^{60}$ SAN Martín (2015), pp. 771-776.

${ }^{61}$ Rivera (1994).

${ }^{62}$ Causa n. ${ }^{\circ}$ 125-2001 (2001); Ospina y Ospina (1994), p. 689; Alessandri Besa (1949), tomo I, p. 549.

${ }^{63}$ Rivera (1994); Alessandri Besa (1949), tomo i, p. 509.

${ }^{64}$ Art. 1699 del Código Civil ecuatoriano.

${ }^{65}$ Coronel y Del Bruto (2011), p. 200; Rivera (1994); causa n. ${ }^{o}$ 240-2001 (2001); causa n. ${ }^{\circ} 332-2011(2011)$.
} 
En relación con la figura de la prestación irrisoria contenida en el Código de Comercio, se dispone que en aquellas prestaciones que no sean conmutativas $^{66}$, el contrato o la cláusula será "absolutamente nulo", permitiendo así a unas de las partes o a un tercero con un interés legítimo en solicitar este remedio, o al propio juez en declararla de oficio. Parece interesante cuestionarse por qué el legislador ha decidido seleccionar este tipo de consecuencia, considerando que no existe objeto o causa ilícita. Sobre todo, porque se ve únicamente involucrado el interés particular, ya que estas podrían decidir o no adaptar el contrato cuando en la nulidad absoluta es imposible realizar tales modificaciones, ya que está en juego el interés general, tal y como se desarrollará más adelante.

Esto lleva a analizar la segunda consecuencia jurídica que se encuentra propuesta en el art. 217 del nuevo Código de Comercio, que es la resolución del contrato por incumplimiento, que es una solución incompatible con la propia nulidad.

\section{Resolución del contrato}

La resolución, de acuerdo con Julio Cesar Rivera, es un régimen que se encarga de la ineficacia de los negocios jurídicos, sea por un hecho sobreviniente imputable a una de las partes contratantes (e.g. incumplimiento de una de las obligaciones pactadas en el contrato) o por una razón extraña a la voluntad de ellas (e.g. el acaecimiento de un hecho futuro e incierto sujeto a una condición resolutoria ordinaria) ${ }^{67}$. El efecto principal de la resolución es la retroactividad de las prestaciones al día de su celebración, lo que obligará a las partes a restituirse lo recibido. En el Código Civil, el régimen de la resolución se encuentra regulada especialmente en los artículos de la condición resolutoria tácita, condición resolutoria ordinaria y del pacto comisorio. En esta sección se centrará en particular en la condición resolutoria tácita puesto que es la que "calificaría" para la prestación irrisoria.

La característica esencial de la condición resolutoria tácita consiste en la verificación del incumplimiento de una de las obligaciones por parte de uno de los contratantes. El art. 1505 del Código Civil prescribe lo siguiente:

"En los contratos bilaterales va envuelta la condición resolutoria de no cumplirse por uno de los contratantes lo pactado. Pero, en tal caso, podrá

${ }^{66} \mathrm{El}$ art. 217 del Código de Comercio ecuatoriano en el penúltimo párrafo, dispone: "Cuando la prestación de una de las partes sea irrisoria en su monto, en consideración a la contraprestación de la otra parte, no habrá contrato conmutativo o de prestaciones correlativas, y en consecuencia el contrato o cláusula será absolutamente nulo". Para algunos se entendería que también tiene lugar la inexistencia del contrato al momento que establece que no habrá contrato conmutativo. Sin embargo, se considera que se está haciendo referencia a que no existe un sinalagma contractual.

${ }^{67}$ Rivera (1994), p. 858. 
el otro contratante pedir, a su arbitrio, o la resolución o el cumplimiento del contrato, con indemnización de perjuicios" ${ }^{\prime 68}$.

Como se puede observar, esta norma hace referencia a una "condición resolutoria". Sin embargo, no opera de igual manera que una condición resolutoria ordinaria, debido a que no resuelve el contraro de manera ipso iure, sino que otorga un derecho alternativo a una de las partes al verificarse el incumplimiento contractual ${ }^{69}$. Este derecho consiste en elegir entre la ejecución forzosa de la obligación por la parte incumplida o la resolución del contrato. De acuerdo con Luis Parraguez, este régimen se presenta por razones de equidad, puesto que se busca restaurar el equilibrio contractual. El fundamento por el que se sostiene esto, es porque los efectos de la acción resolutoria se "constituyen como un mecanismo represivo del incumplimiento injusto"70.

El acreedor puede escoger a su arbitrio entre cualquiera de las dos opciones que le proporciona el artículo, sin que estas puedan ser ejercidas de manera simultánea, pues para el derecho resultan ser incompatibles ${ }^{71}$. En caso de que el acreedor se decida por resolver el contrato, se debe cumplir con varios requisitos: primero, que este haya cumplido con todas sus obligaciones; segundo, que el deudor no haya cumplido con la obligación debida; tercero, que el contrato sea susceptible de resolución y, por último, algunos sostienen que es necesario que el incumplimiento sea relevante o esencial ${ }^{72}$. 208 Asimismo, Luis Parraguez señala que, una vez presentada la acción resolutoria, el juez puede aceptar o puede ocurrir que la niegue cuando la parte incumplida, durante el juicio, decida cumplir con su obligación ${ }^{73}$. De igual manera, esa también ha sido la postura de la Corte Suprema de Justicia en algunas de sus sentencias, señalando:

"la condición resolutoria tácita [...] necesita de declaración judicial ejecutoriada para surtir los efectos determinados por la Ley; y por ello, mientras no haya esa declaración, puede el deudor hacer el pago y frustrar la acción resolutoria [del art. 1505]"74.

Ahora bien, es necesario interpretar qué quiso decir el legislador en el art. 217 del Código de Comercio sobre la prestación irrisoria al momento de disponer: "a petición de la parte legitimada para resolver el contrato [...]"75.

${ }^{68}$ Art. 1505 del Código Civil ecuatoriano.

${ }^{69}$ Larrea (2017), pp. 8-13.

${ }^{70}$ Ibid.; LaCRUZ y otros (1994).

${ }^{71}$ Parraguez (2000).

${ }^{72}$ Ibid.

${ }^{73} \mathrm{Ibid}$.

${ }^{74}$ Ignación Coronel con Enrique Villacreses (1942); Alina Romero Sanchez con Municipio de Quito, Distrito Metropolitano (2004).

${ }^{75}$ Art. 217 del Código de Comercio ecuatoriano. 
Siguiendo las reglas de interpretación del art. 18 del Código Civil, los jueces tienen que atender de forma ordenada las reglas mencionadas en el art. 18. La primera regla señala que cuando el sentido de la palabra es claro se debe observar su tenor literal. En este caso, no se puede seguir esta regla, puesto que en el derecho este término tiene su significado propio, por lo cual lleva a la segunda regla. Esta sugiere que, cuando el legislador haya definido las palabras para determinadas materias, estas deberán entenderse a la definición legal. Como se indicó en párrafos anteriores, el concepto legal de la resolución es la ineficacia funcional de un negocio jurídico por una causa que acontece después a su celebración ${ }^{76}$.

Por eso un sector interpretaría que por la falta de un sinalagma en las prestaciones se "incumpliría" el contrato, y por ello, el legislador ha optado que la mejor opción sería "resolverlo". Sin embargo, no podría existir una resolución en el presente supuesto, porque como se señaló desde un principio, el desequilibrio que ocasiona la prestación irrisoria es congénito, por lo que el negocio nace con un defecto desde su celebración. Por tal razón, no se puede considerar una resolución per se.

No obstante, otros interpretarían el art. 217 del Código de Comercio de acuerdo con la regla número cuarta del art. 18, que determina que el:

"contexto de la ley servirá para ilustrar el sentido de cada una de sus partes, de manera que haya entre todas ellas la debida correspondencia y armonía"77.

$\mathrm{El}$ art. 217 menciona a la nulidad y a la resolución como remedios por los cuales el contrato resultaría ineficaz. Como se ha señalado previamente, estas dos expresiones no tienen el mismo significado, por lo que no habría correspondencia ni armonía en el artículo, si es que el legislador las ha colocado como conceptos distintos. Por ello, no sería desafortunado suponer que quienes redactaron este Código no tenían claro las diferencias entre estos términos, por lo que les consideraron como sinónimos.

Así, con todo lo expuesto se puede concluir que hay dos formas de interpretar el último párrafo del art. 217 del Código de Comercio, como un incumplimiento contractual por no existir una conmutatividad en las prestaciones del contrato, y como una confusión de terminología entre la nulidad y resolución. Se considera que esta segunda interpretación tiene más sentido puesto que no existiría un incumplimiento por la razón mencionada.

Para finalizar, el último remedio, el cual es necesario examinar, es la adaptabilidad del contrato, donde el art. 217 otorga al órgano jurisdiccional la facultad de reequilibrar las prestaciones del contrato, siempre que la parte legitimada para "resolver" le haya solicitado.

\footnotetext{
${ }^{76}$ RAmonda (1997), p. 103.

${ }^{77}$ Art. 18 del Código Civil ecuatoriano.
} 


\section{Adaptabilidad del contrato}

La adaptabilidad o modificación del contrato es la posibilidad que tiene una de las partes en solicitar al juez el reajuste del equilibrio en las prestaciones $\mathrm{y}$, por lo tanto, evitar las consecuencias de la ineficacia del contrato ${ }^{78}$. En la prestación irrisoria del Código de Comercio, este remedio se señala en el último inciso del art. 217, al posibilitar al juez a "adaptar el contrato o la cláusula en cuestión". Esto sería incoherente más que todo con la nulidad absoluta, que imposibilitaría solicitar el reajuste de las prestaciones por parte de uno de los contratantes como un tipo de saneamiento.

De acuerdo con Patricia López, en los casos en los que existe una ventaja excesiva, explotación injusta o prestación irrisoria -como la que atañe-, las partes pueden tener la intención de restaurar el equilibrio inicial conservando el contrato con un contenido distinto ${ }^{79}$. Asimismo, la autora establece que la adaptabilidad alcanza su propósito cuando se toma en cuenta el contenido que debió tener el contrato desde un inicio de acuerdo con una o ambas partes $^{80}$. En concordancia con el principio de buena fe, sería desfavorable y perjudicial mantener tal desequilibrio inicial.

A su vez, José Félix Chamie menciona, en virtud de las circunstancias sobrevenidas, que la parte afectada, que se encuentra legitimada para pedir la resolución del contrato, supone que aún tiene la voluntad y la predisposición de cumplir, pero únicamente si se logra reequilibrar la prestación ${ }^{81}$. No cabría duda suponer que también podría ocurrir en cuestiones de la lesión enorme, excesiva desproporción, o prestación irrisoria, en vista de que los contratos están para cumplirse. Como bien dice el autor antes citado que, en circunstancias especiales de desequilibrio, tanto el equilibrio contractual y el principio pacta sunt servanda

"la equidad de la cooperación las llama, [a las partes], a revisar el contrato y a sanar amigablemente entre ellas cualquier anomalía, antes que abrir el camino a las sanciones que el derecho prevé para estos casos" ${ }^{\prime 2}$.

Las reglas comunes de la adaptabilidad del contrato por desequilibrio inicial se pueden encontrar en varias normas del soft law que sirven como modelo de unificación del derecho contractual, como es el caso de los Principios Unidroit, los PECL, el DCFR, entre otros. En el caso de los Principios Unidroit, como se mencionó en la primera sección, se consagra la posibilidad de solicitar la adaptación del contrato, tanto por petición de la parte legitimada

\footnotetext{
${ }^{78}$ Chamie (2006), pp. 113-140.

${ }^{79}$ López (2018), pp. 131-133.

${ }^{80}$ Ibid.

${ }^{81}$ Chamie (2006), pp. 113-140.

${ }^{82}$ Chamie (2008), p. 117.
} 
para anular el contrato como de la contraparte en modo de frustrar la acción de nulidad ${ }^{83}$, dejando al juez ajustarlo acorde con los "criterios comerciales razonables de la lealtad negocial".

Cabe mencionar que, de manera general, una vez solicitada la acción de adaptabilidad por una de las partes, se estaría renunciando a la acción de nulidad, donde se dejaría sin efecto toda acción anterior hecha en ese sentido $^{84,85}$. Esto confirma que, entre la nulidad y la adaptabilidad, se debe escoger un único remedio más no "acumularlos", como menciona Patricia López, puesto que tienen efectos diversos ${ }^{86}$.

En la legislación ecuatoriana, además de la prestación irrisoria, también se encuentran casos en los cuales se permite una suerte de adaptación o reajuste de las prestaciones del contrato. Estos supuestos son: la cláusula penal enorme (art. 1560 del Código Civi); la lesión enorme en la compraventa y permuta de inmuebles (arts. 1830 y 1840 del Código Civil); el interés convencional excesivo (art. 2109 del Código Civil) y los vicios redhibitorios (arts. 1800 del Código Civily 311 del Código de Comercio).

Por todo lo expuesto, es necesario ahora referirse a un modelo apropiado por el cual sería óptimo que el legislador considere en caso de que este artículo sea modificado en un futuro, y proponer remedios que sean compatibles entre sí.

\section{LA NULIDAD RELATIVA Y LA ADAPTABILIDAD \\ COMO ÚNICOS REMEDIOS CONCILIABLES FRENTE LA PRESTACIÓN IRRISORIA}

La sanción apropiada a la que se debería ajustar el artículo de la prestación irrisoria sería la nulidad relativa o también llamada rescisión en el ordenamiento jurídico ecuatoriano, dado que:

1. no existe objeto o causa ilícita u otra contravención que atente al interés general para producir la nulidad absoluta

2. la nulidad relativa es una sanción en beneficio al interés particular y

3. la adaptabilidad del contrato como una forma de saneamiento por la parte lesionada.

${ }^{83}$ Para que esto ocurra, es necesario una vez que la parte legitimada a anular el contrato notifique a la contraparte su ánimo de resolver el contrato, la otra inmediatamente comunique su ánimo de adaptar el contrato y antes de que la otra no haya actuado razonablemente acorde con dicha notificación.

${ }^{84}$ Así lo mencionan varías normas del soft law, tal es el caso del art. 3.2.10 (2) de los PCCI; art. 4:114 de los PECL; art. 7: 211 del DCFR.

${ }^{85}$ Este régimen no aplicaría en el caso del art. 217 del Código de Comercio ecuatoriano por lo que se establece como sanción a la nulidad absoluta, y su renuncia no estaría permitida por salvaguardar al interés general.

${ }^{86}$ López (2018), pp. 131-133. 


\section{Inexistencia de objeto o causa ilícita u otra contravención que atente al interés general para producir la nulidad absoluta}

Como se ha hecho referencia en los párrafos anteriores, para poder solicitar la nulidad absoluta de un acto, es necesario que tenga como siguientes una de estas causales:

i) objeto o causa ilícita;

ii) ausencia de una solemnidad sustancial exigida por la ley;

iii) que una de las partes contratantes sea un incapaz absoluto o

iv) que se contravenga al orden público o las buenas costumbres.

En caso de estar frente un contrato que contiene una prestación irrisoria, se debe analizar si este cumple con las causales mencionadas, para que pueda ser declarado nulo, de nulidad absoluta. Con respecto a las causales dos y tres no cabe hacer un análisis, pues esta nulidad se produciría por un factor diferente a la prestación, como la incapacidad o la omisión de una solemnidad sustancial. No obstante, es necesario realizar un examen de las restantes: existencia de objeto o causa ilícita y la contravención al interés general o a las buenas costumbres.

En referencia a la primera cuestión, un amplio sector de la doctrina ha definido por objeto del contrato a la obligación en sí misma ${ }^{87}$, la cual puede consistir en un dar, hacer o no hacer ${ }^{88}$. Así concuerda Carlos Morales Guillén 212 al mencionar lo siguiente:

"si el contrato es un acuerdo para constituir, modificar o extinguir una relación jurídica, no es equivocado afirmar que el objeto del contrato es siempre la obligación" 89 .

En conformidad con el Código Civil, existe objeto ilícito cuando se contraviene con el derecho público ecuatoriano (art. 1478); en la enajenación de cosas que no se encuentran dentro del comercio, de los derechos o privilegios intransferibles y de las cosas embargadas (art. 1480) y en las deudas contraídas en los juegos de azar, en la venta de libros cuya circulación no estuviere permitida, y en todos los contratos prohibidos por las leyes (art. 1482).

En el caso de la prestación irrisoria, no se podría hablar propiamente de una vulneración al objeto del contrato, ya que la obligación de este no consiste en que las prestaciones nazcan equilibradas o de reequilibrarlas en caso de requerirlo. Por el contrario, de manera abstracta y general, residirá en pagar un precio en contraprestación de recibir algo a cambio. El objeto del negocio jurídico dependerá frente a qué contrato se esté y cuáles son las prestaciones que las partes hayan pactado, es decir, el dar, hacer o no hacer

\footnotetext{
${ }^{87}$ CASTÁn (2008), pp. 662-663.

${ }^{88}$ ToBOAda (1998), pp. 71-76.

${ }^{89}$ Morales (1994), p. 679.
} 
una cosa determinada. Una parte de la doctrina ha considerado que el fundamento de la ilicitud del acto reside en la mala fe de la parte explotadora, tal como lo sostiene Luis Moisset de Espanés ${ }^{90}$. Sin embargo, se critica esta postura, porque no tiene correspondencia con el objeto del contrato, sino con los motivos por los que llevaron a la persona a contratar, los cuales están más relacionados con la causa.

Por otro lado, también se ha considerado que este tipo de figura afecta a la causa del contrato. Esta en el Código Civil se define como "el motivo que induce al acto o contrato; y por causa ilícita la prohibida por la ley o contraria a las buenas costumbres o al orden público" ${ }^{91}$. Esto ha llevado a la doctrina a discutir sobre qué debe entenderse exactamente por causa, debido a que han sido desarrolladas distintas concepciones como la causa final o jurídica; la causa impulsiva y, finalmente; la causa eficiente. La primera se ha entendido como

"el fin directo e inmediato que persigue el deudor al obligarse, fin que resulta impuesto por la naturaleza del contrato y que, por consiguiente, siempre tiene que ser idéntico en todos los contratos del mismo tipo" ${ }^{92}$.

En cambio, la segunda se la ha definido como "los móviles o motivos individuales y concretos las partes tienen al contratar"93. Para finalizar, la causa eficiente ha sido definida como el origen por el que se producen todos sus efectos, es por tal razón que Guillermo Ospina y Eduardo Ospina entienden que la causa eficiente de cualquier obligación es "el mismo contrato que la genera" ${ }^{94}$.

Una vez realizada esta distinción, cabe mencionar que, para ciertos doctrinarios como Jorge Carranza, la figura de la lesión subjetiva-objetiva, que tienen gran similitud con la prestación irrisoria, vicia a la causa final

"del acto jurídico bilateral conmutativo oneroso, porque al producirse la inequivalencia de las prestaciones queda sin causa eficiente la restante contraprestación, afectándose el equilibrio contractual que es la esencia de aquel linaje de convenciones" ${ }^{\prime 9}$.

No obstante, si se sostiene lo antes dicho se afirmaría que la equivalencia en las prestaciones es una condición necesaria para que exista una causa final. Por tal motivo, Guillermo Ospina y Eduardo Ospina mencionan que

\footnotetext{
${ }^{90}$ Mosset de Espanés (1998), p. 179.

${ }^{91}$ Art. 1483 del Código Civil ecuatoriano.

${ }^{92}$ Ospina y Ospina (2018), p. 258.

${ }^{93}$ Ibid.

${ }^{94}$ Op. cit., p. 257.

${ }^{95}$ Carranza (1969), p. 44.
} 
"la causa de las obligaciones en los contratos sinalagmáticos no está constituida por las obligaciones recíprocas que producen, sino por el cumplimiento mismo de estas" ${ }^{\prime 6}$.

De igual manera, otro sector de la doctrina opina que sí existe un vicio como consecuencia de que la causa es inmoral. Se sostiene que esta inmoralidad se observa cuando el agente celebra el negocio jurídico con el móvil de aprovecharse de la situación de inferioridad en la que se halla su contraparte para obtener una ventaja patrimonial excesiva ${ }^{97}$. Por el contrario, Rubén Stiglitz y María Bernal proponen que el motivo oculto que llevó a una de las partes a aprovecharse de la situación de debilidad de la otra, no se encuentra integrado al campo contractual, puesto que

"no es factible suponer que el lesionado se halla vinculado con lo que ignora. Entonces [...] no puede constituirse en la causa final del acto, sino en el móvil individual que impulsa a contratar"98.

Asimismo, no se estaría frente la hipótesis de una ausencia de objeto o de causa en un contrato que adolece de prestación irrisoria, por las siguientes razones:

i) el objeto del contrato con prestación irrisoria serían las prestaciones a cargo de cada una de las partes;

ii) la causa final o jurídica se verificaría por el cumplimiento de las obligaciones que produce el contrato bilateral-sinaligamático;

iii) la existencia de la causa impulsiva serían todos los motivos intrísecos y personales que llevan a las partes a contratar y, por lo tanto, la existencia o no de ellos quedan fuera del alcance del derecho y

iv) la causa eficiente de la obligación que contiene la prestación irrisoria tendría como causa al propio contrato.

Continuando con la última causal, referente a la contravención al orden público o las buenas costumbres, se ha entendido al primero como aquel conjunto de principios fundamentales de carácter jurídicos, económicos, políticos, sociales y morales sobre los que se basa la organización y estructura de un Estado ${ }^{99} \mathrm{y}$, al segundo, como aquellos principios morales que son comunes en un lugar y tiempo determinado ${ }^{100}$. No obstante, de la distinción teórica que se realiza a los dos términos, se ha concluido por ciertos autores, como Juan Espinoza, que el concepto de buenas costumbres se encuentra subsumido en la definición general de orden público ${ }^{101}$. Por consiguiente,

\footnotetext{
${ }^{96}$ Ospina y Ospina (2018), p. 259.

${ }^{97}$ Papayannis (2005), p. 85.

${ }^{98}$ Stiglitz y Bernal (2017), p. 141.

${ }^{99}$ Espinoza (2002), p. 304.

${ }^{100}$ Ibid.

${ }^{101}$ Ibid.
} 
esta institución tiene como función defensiva la limitación de la autonomía de voluntad de los particulares, impidiendo que sus intereses prevalezcan sobre el interés general.

En el caso de la figura en cuestión, el art. 217 del Código de Comercio ha dispuesto que, en caso de presenciarse una prestación irrisoria en un contrato, este será absolutamente nulo. Por lo que se llegaría a concluir que, en principio, el legislador ha dispuesto como si esta lesión contraviniese al interés general, en virtud de que no hubiera otra razón para que se produzca la nulidad absoluta. Empero, esta es una figura que únicamente estaría afectando al interés de las partes contratantes, dado que no habría interés de una tercera persona en querer dejar sin efecto el contrato o de reequilibrar las prestaciones, más que el interés de la parte perjudicada.

De igual modo, Jorge LLambías estima que se estaría exagerando la protección del interés individual cuando se establece la de nulidad absoluta como sanción en este tipo de lesión, puesto que "se vuelve contra el lesionado interesado, en mantener la eficacia del acto, después de cubierto el daño sufrido" ${ }^{102}$. De hecho, el mismo autor manifiesta que esta vulneración no es más grave que el propio dolo o la fuerza, donde estos últimos tienen como sanción a la nulidad relativa, por lo que debe considerarse este remedio para los negocios que se encuentran lesionados por esta figura.

En efecto, si el art. 217 del Código de Comercio hubiere querido proteger el interés general porque estima que la prestación irrisoria resulta demasiado perjudicial para la sociedad, esta disposición no hubiere considerado en su último párrafo la posibilidad de modificar el contrato, teniendo en cuenta que la afectación al interés social no puede estar a disposición de las partes. Asimismo, Benjamín Piñón expresa lo aludido, al comentar sobre esta figura en la legislación argentina:

"si se permite sanear el acto restableciendo el equilibrio en las contraprestaciones, es porque la reforma ha considerado el acto como afectando al interés privado (al igual que el error, el dolo, la intimidación, etc.) y, por lo tanto, su nulidad debe ser relativa"103.

Un interesante ejemplo que confirma lo señalado, es el caso del Código Civil de Alemania, donde se determina en la sección 138 del $B G B$, que este tipo de lesión vulnera al orden público y, por lo tanto, produce nulidad absoluta ${ }^{104}$. En consecuencia, no permite la posibilidad de adaptar el contrato ${ }^{105}$.

Por lo expuesto, no cabría duda de que, ante la ausencia de objeto o causa ilícita y de contravención al orden público o interés general, la consecuencia

${ }^{102}$ Llambías (1997), p. 300.

${ }^{103}$ Benjamín Piñón citado en Moisset de Espanés (1976) p. 7.

${ }^{104}$ De acuerdo con Ramón Pizarro la nulidad en la legislación alemana es equivalente con la nulidad absoluta del derecho argentino, por lo que el acto no sería susceptible de confirmación o de modificación. Pizarro (1976), p. 46

${ }^{105}$ Art. 138 del $B G B$. 
jurídica apropiada para una futura modificación al artículo de la prestación irrisoria sería la nulidad relativa, debido a que se estaría afectando al interés particular de los intervinientes en el contrato.

\section{La nulidad relativa como una sanción en beneficio del interés particular}

Al contrario de la nulidad absoluta, la nulidad relativa es un tipo de sanción que se produce por la afectación a la "calidad o estado de las personas que los ejecutan o acuerdan" ${ }^{106}$. Tal como indica Arturo Alessandri Besa, este tipo de nulidad se ocasiona "cuando ciertas normas establecidas en favor de ciertas personas son infringidas" 107 . Por consiguiente, al no verse afectado el interés general, se busca proteger solo los intereses particulares que han sido perjudicados.

Por tal motivo, se dispone que este tipo de sanción es, además, un beneficio jurídico que la ley ha otorgado a favor de ciertos individuos, con la finalidad que no se vean afectados por el defecto que presenta el contrato. Arturo Alessandri Besa señala que esto se puede observar en el art. 1700 del Código Civil ${ }^{108}$, el cual prescribe que únicamente se podrá alegar esta nulidad "por aquellos en cuyo beneficio la han establecido las leyes"109. Es por tal razón que, el acto puede ser saneado por la parte interesada, en otras palabras, por aquella persona en cuyo favor se ha otorgado la sanción.

La nulidad relativa se comporta de manera diferente en relación con la absoluta, porque sus consecuencias jurídicas son distintas, estas son:

i) no es susceptible de declararse de oficio, es decir, siempre debe declararse a petición de parte;

ii) solo puede invocarse por aquellas personas en cuyo favor se dispone $\mathrm{y}$, por último,

iii) el acto afectado por esta sanción puede sanearse a través de la confirmación o ratificación y por prescripción ${ }^{110}$.

Jorge LLambías manifiesta que cuando el Código Civil determina que este tipo nulidad no puede ser declarada de oficio, está disponiendo que esta declaratoria "sería contradictoria [con el] sentido tutelar que asume esta nulidad"11, por lo que le corresponde únicamente al interesado "impugnar el acto u optar por su mantenimiento" 112 .

Ahora bien, existe una discusión doctrinaria si la sanción correcta debe ser la nulidad relativa o la rescisión. La mayoría de los autores de la región,

\footnotetext{
${ }^{106}$ Art. 1698 del Código Civil ecuatoriano.

${ }^{107}$ Alessandri Besa (1949), tomo II, p. 675.

${ }^{108}$ Ibid.

${ }^{109}$ Art. 1700 del Código Civil ecuatoriano.

${ }^{110}$ Ibid.

${ }^{111}$ Llambías (1997), p. 542.

${ }^{112}$ Ibid.
} 
como Luis Moisset de Espanés ${ }^{113}$ y Ramón Pizarro ${ }^{114}$, opinan que debería regir la segunda, puesto que se está ante una figura que, en principio, cumple con todos los requisitos de validez, pero no puede producir sus efectos por causa que existe un evidente desequilibrio en sus prestaciones.

No obstante, en la legislación ecuatoriana se ha entendido a estos dos términos como sinónimos. Esto se evidencia a través del último inciso del art. 1698, donde se ordena: "cualquiera otra especie de vicio produce nulidad relativa, y da derecho a la rescisión del acto o contrato" ${ }^{115}$. A consecuencia de esto, se comprueba que el Código Civilusa a ambos términos como equivalentes. Esto también se observa en el art. $1364^{116}$. De igual manera ha ocurrido con la Corte Suprema de Justicia. En uno de sus fallos, sostuvo:

"la acción de rescisión o de nulidad de un contrato es un caso típico de indivisibilidad jurídica porque no puede dividirse o fragmentarse; en otras palabras, un contrato no puede ser válido para uno de los contratantes y nulo para el otro [...]”117.

Indistintamente de que nuestro legislador modifique la sanción del artículo de la prestación irrisoria a la nulidad relativa o a la rescisión, se permitirían que la parte en cuyo beneficio se establece pueda sanear el contrato o la cláusula mediante la adaptabilidad, en razón de que ambos son tratados como términos equivalentes en nuestro ordenamiento jurídico.

\section{La adaptabilidad del contrato como una forma de saneamiento por la parte perjudicada}

El saneamiento de los negocios jurídicos ha sido entendido como la posibilidad de purificar el acto que se encuentra afectado por algún defecto que le impide surtir los efectos que le son propios ${ }^{118}$. La doctrina se ha encargado de establecer cuáles son las formas más comunes en las que se pueden convalidar los negocios, entre ellas se encuentran la ratificación, la confirmación y la prescripción. El art. 1700 del Código Civil establece que la nulidad relativa se podrá sanear por la ratificación o por el transcurso del tiempo ${ }^{119}$. No obstante, se ha hecho la aclaración pertinente que la ratificación y confirmación son terminologías distintas, aunque la legislación no lo haya previsto de esa manera.

${ }^{113}$ Moisset de Espanés (1976), pp. 3-4.

${ }^{114}$ Pizarro (1976), p. 47.

${ }^{115}$ Art. 1698 del Código Civil ecuatoriano.

116 "Las particiones se anulan o se rescinden de la misma manera y según las mismas reglas que los contratos. La rescisión por causa de lesión se concede al que ha sido perjudicado en más de la mitad de su cuota. Las particiones judiciales no se anulan ni rescinden si previamente, por motivos legales, no se anulan las sentencias pronunciadas en ellas". Art. 1364 del Código Civil ecuatoriano.

${ }^{117}$ Causa n. ${ }^{\circ}$ 516-99 (1999).

${ }^{118}$ Ramírez (2008), p. 256.

${ }^{119}$ Art. 1700 del Código Civil ecuatoriano. 
La ratificación es una manera de convalidar el negocio jurídico, por la cual, una persona da el debido consentimiento en aquellos actos en que debía de haber intervenido y no lo hizo, por lo que otra actuó sin la debida representación ${ }^{120}$. Un ejemplo claro de esto es la del representante legal de una empresa, quien puede ratificar el negocio realizado por una tercera persona que no tenía la representación exigida. En cambio, la confirmación es un "acto jurídico por el cual una persona hace desaparecer los vicios de otro acto que se halla sujeto a una acción de nulidad [relativa]" ${ }^{121}$. Tal es el caso cuando existe un vicio de fuerza o dolo en un contrato, la persona legitimada puede confirmarlo cuando aquel haya cesado. Por último, el saneamiento por el transcurso del tiempo, de acuerdo con gran parte de la doctrina constituye la prescripción de la acción, por lo que a modo de sanción prohíbe a la parte afectada alegar la nulidad del acto celebrado, entendiéndose que transcurrido dicho plazo el vicio ha "desaparecido" ${ }^{122}$.

Aclarado esto, la razón que lleva a pensar que la adaptabilidad es una forma de saneamiento, es la renuncia que hace la parte legitimada a anular el contrato y, por lo tanto, a querer conservar el mismo. Esto es, principalmente, porque la parte que tiene derecho para solicitar la nulidad puede tener las intenciones de reequilibrar las prestaciones. En otras palabras, esto significaría hacer desaparecer el defecto que hacía al negocio ineficaz. Lo que resultaría pensar que este tipo de saneamiento es una suerte de confirmación.

218 Esto último ha sido estimado Jorge Mosset Iturraspe, opinando sobre la lesión subjetiva-objetiva de la legislación argentina:

“[...] el reajuste equitativo es una especie de confirmación, puesto que implica sanear el negocio, todo lo cual ha sido decisivo para concluir sosteniendo el carácter relativo de la nulidad” ${ }^{123}$.

De igual manera, Luis Moisset de Espanés indica que esta confirmación solo se puede realizar por la parte perjudicada, una vez que la situación de inferioridad haya desaparecido; por lo contrario, esta convalidación resultaría igualmente ineficaz ${ }^{124}$. No obstante, esto no parece ser lo más apropiado en vista de que el defecto que vicia al negocio no es la situación de dependencia, aflicción económica o inexperiencia de una de las partes, sino el desequilibrio excesivo en las prestaciones ${ }^{125}$.

Opinión contraria ha sido la de Patricia López, en la que manifiesta que la adaptación no puede considerarse un tipo de confirmación, aunque compartan la renunciabilidad del derecho de anular el contrato, puesto que en

\footnotetext{
${ }^{120}$ Alterini (1999), p. 372.

${ }^{121}$ Ibid.

${ }^{122}$ Alessandri Besa (1949), tomo il p. 59; Baraona (2012), pp. 49-62.

${ }^{123}$ Jorge Mosset Iturraspe citado en Moisset DE Espanés (1971), p. 9.

${ }^{124}$ Moisset de Espanés (1976), pp. 16-18.

${ }^{125}$ Barceló (2018), pp. 311-312.
} 
esta última figura "el vicio se sanea y el contrato se valida"126; en cambio, la adaptación tiene como consecuencia que el "contrato original sea remplazado por una versión adaptada o modificada" 127 . Esta posición parece ser forzada, ya que uno de los propósitos de la confirmación es hacer desaparecer el vicio, por lo que en la prestación irrisoria el defecto se purgaría a través de la equivalencia en las prestaciones. Igualmente, Antonio Vodanovic expresa que no es requisito necesario, en la confirmación, que se mantenga el contenido original del acto viciado o que se realice en la forma exigida, a menos que se trate de un acto solemne ${ }^{128}$.

Por lo expuesto se desprende que, la adaptabilidad de la cláusula o del contrato - en la prestación irrisoria-, es una forma de saneamiento, concretamente un tipo de confirmación. Esto es, porque se renuncia al derecho de anular el contrato y se busca eliminar el desequilibrio excesivo que le impide de producir todos sus efectos propios.

\section{LA PRESTACIÓN IRRISORIA:}

hacia una propuesta de Reforma Al ART. 217 del Código de Comercio

Como se puede observar, la redacción del art. 217 del Código de Comercio ecuatoriano tuvo una influencia directa del art. 3.2.7 de los Principios Unidroit, dado que, si se examinan de forma detallada a ambos artículos se puede llegar a la conclusión de que la transcripción del artículo del Código Comercio tiene una gran similitud con el de los Principios Unidroit.

\begin{tabular}{|c|c|}
\hline ART. 3.2.7 PRINCIPIOS UnIDROIT & ART. 217 del Código de COMERCIO \\
\hline $\begin{array}{l}\text { "(1) Una parte puede anular el contrato } \\
\text { o cualquiera de sus cláusulas si en el } \\
\text { momento de su celebración el contrato o } \\
\text { alguna de sus cláusulas otorgan a la otra } \\
\text { parte una ventaja excesiva. A tal efecto, } \\
\text { se deben tener en cuenta, entre otros, los } \\
\text { siguientes factores: } \\
\text { (a) que la otra parte se haya aprovecha- } \\
\text { do injustificadamente de la dependencia, } \\
\text { aflicción económica o necesidades apre- } \\
\text { miantes de la otra parte, o de su falta de } \\
\text { previsión, ignorancia, inexperiencia o falta } \\
\text { de habilidad en la negociación; y }\end{array}$ & $\begin{array}{l}\text { "Se entiende por prestación irrisoria, aque- } \\
\text { lla que es ínfima, inequivalente o desequili- } \\
\text { brada en relación a la contraprestación del } \\
\text { otro contratante. } \\
\text { Para determinar si se trata de una presta- } \\
\text { ción irrisoria, ya sea que constituya la to- } \\
\text { talidad del contrato o una o más de sus cláu- } \\
\text { sulas, se deberá tener en consideración, en- } \\
\text { tre otros, los siguientes factores: } \\
\text { a) Que la otra parte se haya aprovecha- } \\
\text { do injustificadamente de la dependencia, } \\
\text { aflicción económica o necesidades apre- } \\
\text { miantes de la otra parte, o de su falta de } \\
\text { previsión, ignorancia, inexperiencia o falta } \\
\text { de habilidad en la negociación; y, }\end{array}$ \\
\hline
\end{tabular}

${ }^{126}$ LÓPEZ (2018), pp. 148-149.

${ }^{127}$ Ibid.

${ }^{128}$ Vodanovic (2001), p. 187. 


\begin{tabular}{|c|c|}
\hline ART. & ART. 217 DEL CÓDIGO DE COMERCIO \\
\hline $\begin{array}{l}\text { (b) la naturaleza y finalidad del con- } \\
\text { trato. } \\
\text { (2) A petición de la parte legitimada } \\
\text { para anular el contrato, el tribunal podrá } \\
\text { adaptar el contrato o la cláusula en cues- } \\
\text { tión, a fin de ajustarlos a criterios comer- } \\
\text { ciales razonables de lealtad negocial. } 11 \\
\text { (3) El tribunal también podrá adaptar } \\
\text { el contrato o la cláusula en cuestión, a pe- } \\
\text { tición de la parte que recibió la notificación } \\
\text { de la anulación, siempre y cuando dicha } \\
\text { parte haga saber su decisión a la otra inme- } \\
\text { diatamente, y, en todo caso, antes de que } \\
\text { ésta obre razonablemente de conformidad } \\
\text { con su voluntad de anular el contrato. Se } \\
\text { aplicará, por consiguiente, el párrafo (2) } \\
\text { del Artículo 3.10"129. }\end{array}$ & $\begin{array}{l}\text { b) La naturaleza y finalidad del con- } \\
\text { trato. } \\
\text { Cuando la prestación de una de las } \\
\text { partes sea irrisoria en su monto, en consi- } \\
\text { deración a la contraprestación de la otra } \\
\text { parte, no habrá contrato conmutativo o de } \\
\text { prestaciones correlativas, y en consecuen- } \\
\text { cia el contrato o cláusula será absoluta- } \\
\text { mente nulo. } \\
\text { A petición de la parte legitimada para } \\
\text { resolver el contrato, el órgano jurisdic- } \\
\text { cional podrá adaptar el contrato o la cláu- } \\
\text { sula en cuestión, a fin de ajustarlos a crite- } \\
\text { rios comerciales razonables de lealtad ne- } \\
\text { gocial”"130. }\end{array}$ \\
\hline
\end{tabular}

Es notorio que el legislador ecuatoriano ha reproducido en su mayoría el art. 3.2.7, con la introducción de cambios con cierta trascendencia. Estas incorporaciones que se realizaron, de manera consciente o por falta de técnica jurídica, disponen consecuencias distintas a las establecidas en el texto original de los Principios Unidroit. Como se mencionó a lo largo de este trabajo, el art. 217 del Código de Comercio establece tres acciones que resultan incompatibles y con efectos diferentes. Es por ese motivo, que se propone realizar una reforma a dicho artículo para que en la práctica judicial no haya confusiones ni incertidumbres en la aplicación de la sanción correcta frente una prestación irrisoria.

En virtud de brindar una mayor seguiridad jurídica en la aplicación del artículo en cuestión, se presenta a continuación un proyecto de reforma que considera como sanción a la nulidad relativa, misma que se armoniza con la adaptación del contrato. El texto que se sugiere es el siguiente:

Art. 217.- Se entiende por prestación irrisoria, aquella que es ínfima, inequivalente o desequilibrada en relación a la contraprestación del otro contratante.

Para determinar si se trata de una prestación irrisoria, ya sea que constituya la totalidad del contrato o una o más de sus cláusulas, se deberá tener en consideración, entre otros, los siguientes factores:

a) Que la otra parte se haya aprovechado injustificadamente de la dependencia, aflicción económica o necesidades apremiantes de

${ }^{129}$ PCCI.

${ }^{130}$ Art. 217 del Código de Comercio ecuatoriano. 
la otra parte, o de su falta de previsión, ignorancia, inexperiencia o falta de habilidad en la negociación; $y$,

b) La naturaleza y finalidad del contrato.

Cuando la prestación de una de las partes sea irrisoria en su monto, en consideración a la contraprestación de la otra parte, será causa de nulidad relativa del contrato o de una de sus cláusulas.

A petición de la parte legitimada para anular el contrato, el órgano jurisdiccional podrá adaptar el contrato o la cláusula en cuestión, a fin de ajustarlos a criterios comerciales razonables de lealtad negocial.

\section{Conclusiones}

Ciertamente la excesiva desproporción, contenida en los Principios Unidroit, fue una de las figuras jurídicas en la que el legislador del nuevo Código de Comercio se inspiró para redactar el artículo de la prestación irrisoria. Tiene como fundamentos a la inequality bargaining power y la unconscionability doctrine del derecho anglosajón, y a la lesión enorme del derecho continental.

Se puede observar que el legislador que redactó la disposición de la prestación irrisoria, contenida en el art. 217 del Código de Comercio, no puso mayor atención en que la norma cuente con una técnica jurídica adecuada. Como se explicó, dicha norma propone tres consecuencias jurídicas incompatibles: la nulidad absoluta, que busca proteger el interés general y, por lo tanto, no puede sanearse; la resolución del contrato, que se verifica por un incumplimiento contractual y la adaptabilidad del contrato, la cual busca la conservación del negocio.

La nulidad absoluta no puede ser la sanción pertinente para la prestación irrisoria porque no hay objeto o causa ilícita ni tampoco existe una contravención al interés general. En caso que nuestro legislador estimara que la prestación irrisoria es una norma que estaría transgrediendo al orden público ecuatoriano, debería tener en cuenta la imposibilidad de solicitar la adaptación del contrato por la parte perjudicada.

De igual manera, no puede considerarse a la resolución del contrato como una consecuencia jurídica de esta figura, en vista de que no existe un incumplimiento contractual. Por tanto, por la interpretación que se puede realizar al artículo de la prestación irrisoria, de acuerdo con la regla número cuarta del art. 18 del Código Civil, es que, quienes lo redactaron consideraron los términos de 'nulidad' y 'resolución' como equivalentes.

Por otro lado, la adaptabilidad del contrato sí podría ser considerada como un remedio en miras de los intereses de las partes contratantes, ya que permitiría a la parte perjudicada a solicitar la restauración del equilibrio, para la conservación del contrato. No obstante, esto no sería posible en la actualidad, en razón de que se establece como sanción a la nulidad absoluta, la cual imposibilita el saneamiento de los negocios jurídicos. 
Por tal motivo, la sanción correspondiente que se propone, para una reforma futura al art. 217 del Código de Comercio, es la nulidad relativa. Esto debido a que busca proteger exclusivamente los intereses que han sido lesionados y, porque, además, permitiría la adaptabilidad del contrato como una de forma de saneamiento. En consecuencia, la propuesta es que en la reforma que se haga al art. 217 debería omitirse toda referencia a la resolución y a la nulidad absoluta.

\section{BibliografíA CITADA}

Alessandri Besa, Arturo (1949). La nulidad y la rescisión en el derecho civil chileno. Santiago: Ediar Editores Ltda., tomo I

Alessandri Besa, Arturo (1949). La nulidad y la rescisión en el derecho civil chileno. Santiago: Ediar Editores Ltda., tomo II.

Alessandri Rodriguez, Arturo (2003). De la compraventa y de la promesa de venta. Santiago: Editorial Jurídica de Chile, tomo II.

Alias, Siti Aliza \& Zuhairah Ariff Abdul GHadas (2012). "Inequality of Bargaining Power and the Doctrine of Unconscionability: Towards Substantive Fairness in Commercial Contracts". Australian Journal of Basic and Applied Sciences, vol. 6 , issue 11 .

Alterini, Atilio (1999). Contratos: civiles, comerciales, de consumo. Teoría general. Buenos Aires: Editorial Abeledo-Perrot.

Baraona GonzÁlez, Jorge (2012). La nulidad de los actos jurídicos: Consideraciones históricas y dogmáticas. Bogotá: Grupo Editorial Ibáñez.

Barceló Compte, Rosa (2018). Ventaja injusta y protección de la parte débil del contrato. Memoria para optar al grado de Doctor. Barcelona: Universidad de Barcelona, Facultad de Derecho.

Barceló Compte, Rosa y Gemma Rubio Gimeno (2014). "De la Gross Disparity a la Unfair Explotaition: Modelos para una futura regulación en supuestos de desequilibrio económico contractual". Revista de Direito Brasileira, vol. 9.

Barnhizer, Daniel (2005). "Inequality of Bargaining Power". University of Colorado Law Review, vol. 76.

Bonell, Michael J. (1995). "Policing the International Commercial Contract against Unfairness under the UNIDROIT Principles”. Tulane Journal of International and Comparative Law, vol. 3.

BordA, Alejandro (2003). "La lesión a través de las XVII Jornadas Nacionales de Derecho Civil". Revista Hágase Saber, n. ${ }^{\circ} 12$.

Bosch Capdevila, Esteve (2012). “Causas de invalidez del contrato”, en Antoni Vaquer Aloy, Esteve Bosch Capdevila y María Paz Sánchez González, (coords.). Derecho europeo de contratos. Libro II y IV del marco común de referencia. Barcelona: Atelier, tomo I. 
Carranza, Jorge (1969). El vicio de la lesión en la reforma del Código Civil. Buenos Aires: Editorial Abeledo-Perrot.

Carranza Álvarez, Cesar (2006). "La Excesiva Desproporción en el Contrato a través de los Principios del Unidroit". Boletin del Ministerio de Justicia, n. ${ }^{\circ} 2026$.

Castán Tobeñas, José (2008). Derecho civil español, común y foral. Madrid: Editorial Reus, tomo III.

Chamie, José Félix (2008). "Equilibrio contractual y cooperación entre las partes: el deber de revisión del contrato". Revista de Derecho Privado, n. ${ }^{\circ} 14$.

Chamie, José Félix (2010). "Rescisión por lesión enorme: El problema del origen". Revista de Derecho Privado, vol. 19.

Coronel Jones, Cesar y Oscar Del Bruto Andrade (2011). "Nulidad e inexistencia de los Actos Jurídicos en el Derecho Ecuatoriano (I)". Revista de Derecho Ius Humani, vol. 2.

Du Plessis, Jacques (2009). "Validity", in Stefan Vogenauer \& Jan KleinheisTERKAMP (eds.). Commentary of the Unidroit Principles of International Commercial Contracts (PICC). Oxford: Oxford University Press.

EsPinOza EsPinOZA, Juan (2002). "El orden público y las buenas costumbres en la experiencia jurídica nacional”. IUS ET VERITAS, n. ${ }^{\circ} 24$.

Kramer, Ernst (1999). "Contractual Validity According to the UNIDROIT Principles". European Journal of Law Reform, vol. 1, No 3.

Lacruz Bardejo, José L. y otros (1994). Elementos de derecho civil. Barcelona: Editorial José María Bosch, tomo II.

LaRrea Fradejas, Nicolas Esteban (2017). La relevancia del incumplimiento contractual como presupuesto para el ejercicio de la acción resolutoria. Memoria para optar al título de abogado. Quito: Universidad San Francisco de Quito, Facultad de Jurisprudencia.

LLAmbías, Jorge (1997). Tratado de derecho civil: Parte general. Buenos Aires: Editorial Abaledo-Perrot, tomo II.

LÓPEZ DíAz, Patricia (2015). "El principio del equilibrio contractual en el código civil chileno y su particular importancia como fundamento de algunas instituciones del moderno derecho de las obligaciones en la dogmática nacional". Revista Chilena de Derecho Privado, n. ${ }^{\circ} 25$.

López DíAz, Patricia (2018). "La adaptación del contrato como medio de tutela precontractual en el Código Civil chileno". Revista de Derecho, vol. 31.

Magallón IbarRa, Jorge (1997). Instituciones del derecho civil. México DF: Editorial Porrúa, tomo VI.

Martins Zanitelli, Leandro (2011). "A reprocidade nos contratos: uma análise expressivista". DIREITO GV Law Review, vol. 7, issue 1.

Moisset de Espanés, Luis (1971). "El régimen de la lesión y las Quintas Jornadas Nacionales de Derecho Civil”. Zeus, tomo 77. Rosario. D-11. 
Moisset de Espanés, Luis (1976). "Las acciones nacen de la lesión”, en Luis Moisset de Espanés. La Lesión y el nuevo artículo 954 del Código Civil. Córdoba: Universidad Nacional de Córdoba.

Moisset de EspanÉs, Luis (1998). "Lesión: Elemento y Naturaleza Jurídica". THEMIS Revista de Derecho, n. ${ }^{\circ} 38$.

Morales Guillén, Carlos (1994). Código Civil, concordado y anotado. La Paz: Editorial Gisbert, tomo I.

Ospina Fernandez, Guillermo y Eduardo Ospina Acosta (1994). Teoría general de los contratos y de los demás actos o negocios jurídicos. Bogotá: Editorial Temis S.A.

Ospina Fernandez, Guillermo y Eduardo Ospina Acosta (2008). Teoría general del contrato y del negocio jurídico. Bogotá: Editorial Temis S.A.

Papayannis, Diego Martin (2005). "La Lesión subjetiva-objetiva en el Derecho Argentino". Lecciones y Ensayos, vol. 81.

Parraguez Ruiz, Luis (2000). Manual de derecho civil ecuatoriano, libro cuarto: Teoría general de las obligaciones. Quito: Talleres Gráficos de la Universidad Técnica Particular de Loja, vol. 1.

Pizarro, Ramón (1976). "Aspectos procesales de la Lesión Subjetiva”. Revista Notarial: Colegio de Escribano de la Provincia de Córdoba, n. ${ }^{\circ} 31$.

224 RAMírez BAQUERO, Edgar (2008). La ineficacia en el negocio jurídico. Rosario: Universidad del Rosario.

Ramonda, Margarita (1997). "La resolución por incumplimiento". Revista Electrónica Cartapacio de Derecho, vol. 2.

Rivera, Julio Cesar (1994). Instituciones del derecho civil. Parte general II. Buenos Aires: Editorial Abeledo-Perrot.

RiverA, Julio Cesar (s/a). "Elementos y prueba de la lesión subjetiva”. Revista El Derecho, tomo 74.

San Martín Neira, Lilian C. (2015). "La teoría de la inexistencia y su falta de cabida en el Código Civil chileno". Revista Chilena de Derecho, vol. 42.

Stiglitz, Rubén y María Bernal Fandiño (2017). "La lesión enorme en Argentina y Colombia: un estudio comparado". Revista de Derecho Privado, vol. 33.

Toboada Córdova, Lizardo (1988). "Causales de nulidad del acto jurídico". THEMIS Revista de Derecho, n. ${ }^{\circ} 11$.

Vaquer Aloy, Antoni, Esteve Bosch Capdevila y María Paz Sánchez González (coords.) (2012). Derecho europeo de contratos. Libro II y IV del Marco Común de Referencia. Barcelona: Atelier, tomo I.

Vodanovic, Antonio (2001). Manual del Derecho Civil: Segundo volumen de las partes. Santiago: Editorial Jurídica ConoSur Ltda.

Yildirim, Ahmet Cemil (2008). "Subjective Reasons of Gross Disparity and the Presumption of Profesional Competence: A contradiction in the lex mercatoria”. Murdoch University elaw Journal, vol. 15, issue 1. 
ZANITELLI, Leandro (2011). "A reprocidade nos contratos: uma analise expressivista". Direito GV Law Review. vol. $7, \mathrm{n}^{\circ} 1$.

\section{Normas citadas}

Código Civil Federal Mexicano, 31 de agosto de 1928.

Código Civil alemán, 2 de enero de 2002.

Código Civil brasileño, 10 de enero de 2002.

Código Civil ecuatoriano, 24 de junio de 2005.

Código Civil italiano, 4 de abril de 1942.

Código Civil suizo, 1 de enero de 1912.

Código Civil y Comercial de la Nación argentina, 8 de octubre de 2014.

Código de Comercio ecuatoriano, 29 de mayo de 2019.

Comisión De Derecho Europeo de los contratos: "Principios de Derecho Europeo de los Contratos" (2002).

Grupo de estudio sobre un Código Civil europeo. "Marco Común Referencia para el Derecho Privado Europeo" (2009).

Instituto Internacional para la Unificación del Derecho Privado: "Principios UNIDROIT sobre Contratos Comerciales Internacionales” (2016).

Uniform Comercial Code american, 1952.

\section{Jurisprudencia citada}

Alina Romero Sánchez con Municipio de Quito, Distrito Metropolitano. Corte Suprema de Justicia del Ecuador, Tercera Sala de los Civil y Mercantil, 29 de noviembre de 2004, G.J. Serie XVII, N. 1.

Causa n. ${ }^{\circ}$ 125-2001. Corte Suprema de Justicia del Ecuador, Segunda Sala de lo Civil y Mercantil, 26 de marzo de 2001, G.J. Serie v, N. 17.

Causa n. ${ }^{o}$ 228-2004. Corte Suprema de Justicia del Ecuador, Segunda Sala de lo Civil y Mercantil, 24 de abril de 2006, G.J. Serie XVIII, N. 2.

Causa n. ${ }^{o}$ 240-2001. Corte Suprema de Justicia del Ecuador, Primera Sala de lo Civil y Mercantil, 26 de junio de 2001, G.J. Serie XVII, N. 9

Causa n. ${ }^{\circ}$ 332-2011. Corte Suprema de Justicia del Ecuador, Sala de lo Civil, Mercantil y Familia, 16 de mayo de 2011.

Causa n. ${ }^{\circ}$ 516-99. Corte Suprema de Justicia de Ecuador, Primera Sala de lo civil y Mercantil, 16 de octubre de 1999.

Ignación Coronel con Enrique Villacreses. Corte Suprema de Justicia del Ecuador, Primera Sala de lo Civil y Mercantil, 18 de febrero de 1942, G.J. Serie VI, N. 10. 


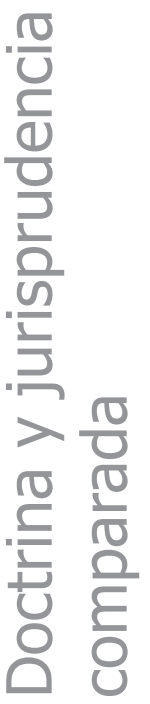

226
SigLA Y ABREVIATURAS

art. artículo

arts. artículos

BGB Bürgerliches Gesetzbuch

coords. coordinadores

DCFR Draft Common Frame of Reference

e.g. exempli gratia,

G.J. GacetaJudicial

Ibid. Ibidem

https Hypertext Transfer Protocol Secure

Ltda. limitada

n. ${ }^{\circ}$ a veces $\mathrm{N}^{\mathrm{o}}, \mathrm{n}^{\mathrm{o}}, \mathrm{N}$ número

op. cit. opere citato (obra citada)

p. página

PECL Principios de Derecho Europeo de los Contratos

pp. páginas

PCCI a veces Principios Unidroit Principios Unidroit sobre Contratos Comerciales Internacionales

SA Sociedad anónima

s/a sin año

UCC Uniform Commercial Code

vol. volumen 